https://jurnal.ugm.ac.id/rubikon

\title{
DIFFERENT TYPES OF STEREOTYPE TOWARD LGBT AS MINORITY ON AMERICAN ONLINE NEWS
}

\author{
Aprilya Indah R. \\ e-mail: aprilyaindah64@gmail.com \\ Dewi Haryani Susilastuti \\ Universitas Gadjah Mada \\ e-mail: dewi.haryani.s@ugm.ac.id
}

\begin{abstract}
This research discusses the stereotypes of LGBT in the United States, which appear on American online news. This research works under Post-Nationalist American Studies by applying the gender socialization approach and stereotype theory. Qualitative research aims to seek the differences of stereotypes experienced by LGBT in the United States. The online news portals selected include The New York Times, Washington Post, and USA Today. These news portals are chosen due to their neutrality and trustworthiness as online news portals for American society. By examining the data, the researcher found that the stereotypes experienced by Lesbian, Gay, Bisexual, and Transgender in the United States are different from one another. The findings and discussion show that Transgender stereotypes in the United States are more negative rather than others. In short, LGBT is mostly considered as a unity; however, it faces different challenges due to their minority status in the middle of American society.
\end{abstract}

Keywords: American online news; gender socialization; LGBT; minority; stereotype

DOI $\quad$ : https://doi.org/10.22146/rubikon.v7i1.62510

Available at https://jurnal.ugm.ac.id/rubikon/article/view/62510

This work is licensed under a Creative Commons Attribution-ShareAlike 4.0 International License

\section{INTRODUCTION}

The number of outspoken Lesbian, Gay, Bisexual, and Transgender or $L G B T$ in the United States is increasing. As Gates (2017) reported, the latest report of the LGBT population in the United States increases from $3,5 \%$ in 2012 to $4,1 \%$ in 2016 (p. 1221). The
Article information

Received: 24 January, 2020

Revised: 7 February, 2020

Accepted: 21 February, 2020

development may increase from time to time. This increase might be possible because of the struggle of LGBT through some movements in the United States.

Historically, the first case of the same-sex activity happened in the United States in 1566, receiving a death sentence, as same-sex was 
banned by law and traditional custom (Morris, 2009). Moreover, the United States military also contributed to eliminating the LGBT population. The United States military began to discharging lesbians and gays then prevented them from serving, damaging their ability to obtain civilian employment (Morrow, 2001, p. 156).

However, LGBT in the United States began to show their sexual identity in the early $20^{\text {th }}$ century. Morris (2009) states that, with the rise of blues music in the early 1920s, African American women showcased varieties of lesbian desire, struggle, and humor; these performances and male and female drag stars led to the introduction of gay bars in the United States. Since the population of LGBT started to increase, the organizations which support LGBT as an oppressed cultural minority also began to establish.

Some popular organizations were supporting the LGBT community during that time. Some of them were Mattachine Society- founded in 1950 by Harry Hay and Chuck Rowland, One, Inc.- - founded in 1952, and the first lesbian support network named Daughters of Bilitis-founded in 1955 by Phyllis Lyon and Del Martin (Morris, 2009). Those organizations worked to support and give safety to the LGBT community, which faced prejudices and discriminations.

Bronski (2011) claims hatred towards LGBT was at its peak in the 1960s. There were physical harassment, psychiatric lockup as well as jail, losing jobs (p. 21-22). Moreover, it worsened when the American Psychiatric Association defined LGBT as mentally sick, criminal, and immoral. However, the Civil Rights Movement that began in the 1960s gave hope to LGBT as part of the minorities in the
United States. Therefore, the Civil Rights Movement became the beginning of other movements. The independence of the LGBT community was further strengthened by the existence of the Stonewall Riots.

Nelson (2015) states that The Stonewall Riot, which occurred in 1969, was the origin for the stand against oppression in the LGBT; LGBT and their supporters rallied and protested for equal rights by forming organizations hosting public demonstrations. Stonewall Riot was perhaps the most significant movement in fighting for the rights of LGBT in the United States (p. 21). Morrow (2001) claims that it was the first time LGBT rose against police oppression and became actively resistant to institutionalized antiLGBT violence (p. 160). Through this movement, LGBT became more struggling to voice their rights for equality in the United States. Furthermore, Stonewall Riot also led to the emergence of Gay Pride, held in June every year in the United States (Nelson, 2015, p. 23).

LGBT started to be accepted gradually after the involvement of politicians. Morris (2009) claims that LGBT began to get approval by the United States after the first out Gay minister was ordained by the United Church of Christ in 1972. Since a more powerful person turned out to be Gay, people started to be less discriminating against LGBT at that time. Furthermore, Waites and Kollman (2009) also argue that since gay and lesbian movements in the United States happened in the 1960s, the LGBT community became more open about their identity and started to struggle more for their rights (p. 2).

Furthermore, LGBT is not a single group. LGBT consists of people with different sexual 
orientations. Some people are openly gay or lesbian, while there are also those who are in the closet. Kushnick (2010) explains that the term 'in the closet' used since the late of 1960s which originally refers to a small private room (p. 678). This idea means to the sense of hiding a fact or keeping a secret about something. Therefore, a person who is hiding the fact that they are gay or lesbian has been described as 'in the closet.' People who are openly lesbian or gay and those who are 'in the closet' would experience different treatment and challenges. It also occurs in bisexual and transgender people. Moreover, the social class would also affect the treatment experienced by LGBT within society.

The existence of prejudices toward LGBT in the United States even though there were many movements that happened throughout the decades. Many supports raise awareness that LGBT still became an issue that might be difficult to be eliminated. Thus from the research background, the researcher analyzes LGBT stereotypes in the United States by applying the stereotype theory by Henry Tajfeil. The researcher uses some selected stereotypes which appear in American online news: The New York Times, Washington Post, and USA Today. These news portals are chosen due to their high level of factual reporting, generally trustworthy for information, and have a good reputation in World Press Rank (Media Bias/Fact Check, 2019). Moreover, the researcher chooses news in online newspaper throughout 2019-2020 in order to indicate the latest news in the United States and also considering the availability of data.

In addition, the researcher also analyzes the difference of stereotypes toward Lesbian, Gay, Bisexual, and Transgender. Thus, this research asserts that stereotypes against Lesbian, Gay, Bisexual, and Transgender are way too different one and other even though LGBT is considered a single unity minor community.

In doing the analysis, this research utilizes the Post-nationalist American Studies paradigm, which concerns cross-cultural communication, race and gender, global and local identities, and the complex tensions between symbolic and political economies (Rowe, 2000). It means that this particular paradigm discusses the minority issues in American society, which may deal with racial, gender, and other minor issues in the United States. Thus, under Post-nationalist American Studies, this research is no longer celebrates American myths since it discusses LGBT as a problematic minority issue in the current American society.

Furthermore, the researcher uses a sociological approach, which specifically is the gender socialization approach. Gender socialization aims to determine how and why males and females act differently, and the socialization process begins at birth (Carter, 2014 , p. 244). Therefore, everyone is taught to accept their gender roles and sexuality. Based on gender roles, a male is expected to be masculine while a female is expected to be feminine. Due to gender socialization, society expected people to appear and behave based on their gender roles and sexuality. However, minorities, like LGBT, mostly do not appear and act based on gender socialization. Thus, this research discusses LGBT stereotypes in the United States which appear on American online news: The New York Times, The Washington Post, and USA Today. 
In this research, in order to examine LGBT stereotypes in the United States, it is essential to understand the stereotype theory. Mark and Ko (2019) state that stereotypes refer to beliefs about the attributes and behaviors of individuals and or groups (p. 2). Moreover, Tajfel (1963) adds that "the less specific information one has about an individual, the greater will be the tendency to assign to him the characteristics which are assumed to be those of his group" (p. 12). Therefore, stereotypes can be wrong. Tajfel (1963) reveals that through stereotypes, people characterized human groups; these characterizations might stable for long periods of time or tend to change to some extent as functions of social, political, and economic changes (p. 4-5). For example, the stereotype of women as weak and uneducated back then, but as technology develops, many educated women have successful careers.

According to Tajfel (1963), the stereotype is divided into two categories; neutral stereotypes and prejudiced stereotyping (p. 8). In other words, the types of stereotypes are both positive and negative stereotypes. Tajfel (1963) claims that neutral stereotypes have no emotional involvement; it represents no more than a moderately useful classifying device for lack of anything better to rely on (p. 12). For example, when a White has no bias toward other Whites in public places in the United States. In contrast, prejudiced stereotyping happens when a person or group of people labeling others with negative characteristics. In his study, Tajfeil (1963) gives an example of discriminatory stereotyping; in some American experiments, it has been shown that groups of Americans have less positive stereotypes toward Negroes when they are presented with a series of photographs of Negroes and whites (p. 9). Thus, the neutral stereotype would have no impact while, in contrast, prejudiced stereotyping would bring adverse effects, which might lead to discrimination.

This research then uses qualitative as the method with descriptive type research. According to Jackson (1995), qualitative research asserts verbal description and explanations of human behavior. The researcher uses descriptive type research on describing the findings to get the accurate depiction of a population since the aims of descriptive research is to describe in order to make estimations about some populations ( $\mathrm{p}$. 18). It means that qualitative research is conducted based on descriptive data and it further relies on the researcher's interpretation of the data.

Moreover, in conducting this research, it needs data sources divided into two; primary and secondary sources. The primary sources are American online news articles from The New York Times, The Washington Post, and USA Today throughout 2019-2020, which contain stereotypes toward LGBT in the United States. The secondary sources are taken from other printed and unprinted references from international journal research, books, websites, and electronic books which related to the topic of discussion.

\section{DISCUSSION}

In order to discuss the differences of stereotype toward LGBT in the United States and examining the reason of it, the researcher investigates the stereotypes toward Lesbian, Gay, Bisexual, and Transgender which featured on selected American online news. Thus, the findings and discussion part, is classified into four parts: Lesbian stereotypes, Gay stereotypes, Bisexual stereotypes, and Transgender stereotypes. Furthermore, the 
researcher explores the differences of stereotypes toward LGBT in the United States.

\section{Lesbian Stereotypes on American Online News}

Lesbians are usually stereotyped as straight-forward. The context of straightforward means that being too honest and direct in stating what their thought (Bull, 2008). In discussing the stereotype of lesbians, they are often depicted as straight-forward. For instance, it is characterized by Santana Lopez on the American television series Glee-an American popular television series tells about a group of high school students who try to escape from the harsh realities by joining a choir club (IMDb, 2009).

In the series, Santana came out as a lesbian after one of her classmates knew that she is a lesbian. Through the series, the character of Santana is depicted as a mean straight-forward girl. The depiction of the surface of Santana Lopez on Glee as a straightforward who is not afraid to admit her sexuality as a lesbian inspires a lot of people. As The Washington Post (2020) illustrates, "For many young fans of Glee, Santana served as a role model not in the traditional sense her wit, while admirably sharp, was often weaponized - but because her on-screen exploration of identity validated their own." Through the news article, Santana is a lesbian high school student who does not feel afraid to admit her sexuality; also, she is not scared of being ostracized by her surrounding environment.

Furthermore, it shows that, in American society, especially on online media, lesbians are often labeled as bold or straight-forward characters with less respect or awareness toward their surroundings. By deeply looking at this news article, the analysis of Santana's character on Glee resembles this stereotype of lesbian, has already been embedded as part of the characteristic of lesbian in the United States. Then, The Washington Post compares the existence of this particular stereotype in the current American society.

Besides straight-forward, one of the most notable stereotypes of lesbians in American society is good in sports, the field that is usually related to men. In this case, women's soccer has gained a lot of attention and popularity in American society. In fact, in contrast to the American men's soccer team, the American women's soccer team dominates international competitions by winning the FIFA Women World Cup several times (The New York Times, 2019). Uniquely, the members of the women soccer team in the United States are dominated by lesbian and bisexual females.

Lesbians are stereotyped as a good athlete because lesbians are usually considered more masculine rather than heterosexual women. These stereotypes are proven by research focus on lesbian stereotypes. Research conducted by Geiger, Harwood, and Hummert (2006) indicates that lesbian stereotypes are athletic, powerful, and explicitly masculine (p. 171). These studies as facts of supporting stereotypes toward lesbians as featured in the news article. The discussion of this particular stereotype toward lesbians in American society shows that lesbian women are often labeled as "more masculine than heterosexual women." As The New York Times highlighting this issue on its media platform, it reveals that this type of stereotype does exist in the current American society. 


\section{Gay Stereotypes on American Online News}

Gay as part of a minority in the United States is usually stereotyped as full of empathy. It means that gay people are considered as more understanding and respecting toward other people compared to heterosexuals. Moreover, as part of the minorities, gay has surely experienced some difficulties and challenges which make them feel empathy toward their community, in this case, other gay people. Therefore, gay would concern other minorities and more respecting people due to their identical situation in the middle of American society.

Pete Buttigieg was a candidate for the nomination in the 2020 United States presidential election. Pete Buttigieg started his presidential campaign in 2019. Based on The New York Times (2020), he is known as gay, which made him the first United States gay presidential candidate. He gained some supports from his supporters, which mostly came from the minorities, especially from the LGBT community. It was shown through support by his supporters during his campaign. Even some supporters approached him at his campaign events while crying. Buttigieg's supporters believe that the fact of him as gay making him more approachable and more concerned about minorities in the United States. As The New York Times (2020) states:

Buttigieg's sexual orientation can be woven into his personal narrative to powerful effect, humanizing him, making him more approachable rather than less, forging a bridge to other minorities, establishing a familiarity with struggle and thus a capacity for empathy.

The discussion surrounding the stereotype of gay figures like Pete Buttigieg as full of empathy can be seen on the New York Times article above. It shows that American online media often emphasizes the discussion toward the sexual orientation of political figure as a stereotype in which it resembles that Pete Buttigieg is able to represent the voice of LGBT and other minorities in American stage of politics.

Other than being stereotyped as full of empathy, gay is also stereotyped as a sensible person who represented on American online news. The researchers of UW News (2017) found that gay participants who were married reported have better physical and mental health. In short, homosexual marriage gives a higher level of satisfaction and happiness rather than heterosexual marriage. In order to investigate about homosexual marriage, The New York Times (2020) interviewed their gay readers to reveal about the dynamics of gay relationship:

I am in a same-sex relationship, and we are regularly flummoxed by how our heterosexual parent friends don't split nighttime child care and sleep loss...In our house, parents are parents. There is no artificial distinction like fathers do this and mothers do that.

Based on the interviews, most of the participants utter that they feel happier in gay marriage because they are able to get away from traditional gender roles and expectations. Due to traditional gender roles, men are expected to work while women are expected to do household and child caring. In homosexual marriage, based on the interview, they argue that households are carried out by both parties fairly so it does not only burdens one party. Because of that, homosexual marriage is claimed to be healthier and happier than heterosexuals since both parties are being sensible. 
By understanding the issue, gay is viewed as more sensible. In gay marriage, both parties are more understanding of each other and do not impose a duty on only one party. Both parties help and understand each other, which make a gay marriage are viewed as healthier than heterosexuals. Thus, this creates a stereotype that gay is sensible.

Furthermore, gay in the United States is also stereotyped as more fashionable than a straight man. This can be seen from an article in The New York Times, which discusses Jared Polis. Jared Polis is a director and producer in the United States who is increasingly known after being governor of Colorado. Even though Colorado is known for resisting anti-gay policies, Jared Polis' voters claim that they did not vote for Polis because he is gay. In this case, Colorado people assume that he did not represent the stereotype of gay since he is not a well-dressed man. As stated from The New York Times (2019):

He does not conform to the clichéd gay stereotypes ... GQ called him the worstdressed congressman ever, though he is improved his style a bit since then ... all gay men are stylish, they dance well, they yada yada yada.

The stereotypes of gay for being stylish seem to be quite well known. Therefore, by understanding the issue, in American society, being fashionable is one of the stereotypes toward gay people that are sometimes discussed on the media. In Polis' case, it is used to a political issue. Thus, along with being sensible and full of empathy, this stereotype is also attached to gay people in American society.

In contrast, gay is also stereotyped as unreligious in the United States. The issues between faith in religion and homosexuality are complicated in the United States. Most Americans, which are Christians, have regarded homosexuality as morally wrong. Subhi and Geelan (2013) state that since the beginning of Christianity, most Christians have already had a bias toward homosexuality. As reported from The New York Times (2020), through Daniel Karslake's documentary, which follows Christian families discussing about their testimonies toward homosexuality, all of them revealed their disagreement against homosexuality also the legalization of same-sex marriage in the United States; most of them stated that being gay is embarrassing because it contradictory against bible. Based on Daniel Karslake's documentary, it appears that there are many Christian families still opposing homosexuality and strictly prohibit their generation from being homosexuals.

In short, by understanding the issues, gay stereotype in the United States is unreligious since the issues assert that gay is sinful, strictly prohibited in religion because it violates the rules in bible, and also viewed as possessed by demon. Moreover, the studies also affirm the gay stereotype in the United States as unreligious.

\section{Bisexual Stereotypes on American Online News}

Bisexual is also part of the minorities in the United States due to social and religious stigma. Bisexual is sexuality which has the potential to be attracted romantically and sexually to people of more than one sex or gender (Ochs, n.d.). Since bisexual's interest in people is more than two sexes or genders, it makes bisexual look quite more unique than lesbian or gay. However, because of that, 
society's stereotype towards bisexual is also more pessimistic than lesbian or gay.

As stated from The New York Times (2019), in the United States bisexual is stereotyped as negative such as a transitional stage and a cover for promiscuity. Because bisexual is interested in more than one sexes or genders, that is why they are stereotyped as being in a transitional stage, since their sexuality are neither heterosexual nor lesbian or gay-whose interested for only one sex or gender. Moreover, the stereotype of promiscuous is also associated with bisexual because of bisexual's tendencies to two sexes or genders.

Based on the issue, bisexuals in the United States are stereotyped as people who are confused about their sexuality, because bisexuals are attracted to both men and/or women also both genders. Because of that, bisexuals in the United States are also stereotyped as people who involved in promiscuity.

\section{Transgender Stereotypes on American Online News}

Transgender refers to people who generally refuse to take their gender binary as given (Vidal-Ortiz, 2008, p. 435). Since transgender refusing to take their gender binary as birth, they behave and look like their opposite gender binary. As an example, a Transwoman - who is actually a man, changes his appearance and behave like a woman. Because of this, the stereotype of transgender in the United States is as an impersonator of their opposite gender.

The anti-Trans community names TransExclusionary Radical Feminists or TERFs for short. TERFs is an anti-Trans community- based in the United States for those who hold such views deny the validity of transgender people and transgender identities (USA Today, 2020). TERFs believe that Transwomen are not counted as women, "The women who are accused of being impostors these days are often trans women" (The New York Times, 2020). Due to their beliefs, TERFs' stereotypes toward Transgender are always negative. Besides stereotyping Transgender as an impersonator of women, TERFs also call Transgender as cartoons of reality because the femininity performance depicted by Transgender is unnatural and also look it is designed for male satisfaction only. Other than TERFs, there is another radical feminist community in the United States names The Women's Liberation Front or known as WoLF in short.

WoLF is a radical feminist organization based in the United States, established in 2014 and aimed at the total liberation of women (Women's Liberation Front Official Website, 2014). One of the agendas of WoLF is to reject the existence of transgender since they believe that Transwomen are not women. Moreover, they claim that:

there is no male can assume female chromosomes and life history/ experiences...transgender women reinforce gender stereotypes and pose a threat to gender equality (The Washington Post, 2020).

In summary, the stereotype of Transgender in the United States is Transgender as an impersonator of another gender. Based on the issue, Transwomen are considered as not women because they behave unnaturally feminine. In short, even though Transgender appears as their gender desires, they are still stereotyped as impersonators 
because their biological identities are still based on their birth sex.

The stereotypes of transgender in the United States are mostly negative. Besides being an impersonator, the stereotype of transgender is abnormal. It happens because transgender changes their identity to its opposite, and it is considered weird and being abnormal. The United States Department of Housing and Urban Development secretary, Ben Carson, confirms his disapproval of transgender in front of media during his visit at the Union Rescue Mission in Skid Row area of downtown Los Angeles, the United States. The internal meeting discusses women's homeless shelters in the United States. During the conference, media revealed that Ben Carson keep alluding the transgender by mentioning transgender women as big and hairy men; this statement remarked upset feeling of the staff who present at the meeting (The Washington Post, 2019).

Based on the issue, the stereotype of Transgender in the United States is abnormal. Transwomen behave and look like women while Transmen behave and look like men; because of that, it makes Transgender looks too visible which make them are stereotyped as unusual and abnormal.

Based on the findings, the researcher found that lesbian has two cases are included in neutral stereotypes such as being straightforward and athletic. Moreover, gay has three instances that included in neutral stereotypes; gay as full of empathy, fashionable and sensible person, while gay also has one case is included in prejudiced stereotype-gay as unreligious.

In contrast, by examining the findings, the stereotypes of bisexuals and transgender in the
United States are included in prejudiced stereotyping. Bisexual in the United States is stereotyped as promiscuous, while transgender is stereotyped as impersonator and abnormal. Based on the issue, bisexual is stereotyped negatively because of their attraction to both sexes and genders. Unlike transgender, bisexuals rarely got negative stereotypes and discrimination in the United States because their appearance is not as conspicuous as transgender. This is proven by a study conducted by Gazzola and Morrison (2014), which indicates that transgender in the United States is stereotyped as abnormal because of their weirdness by wearing feminine clothing - and vice versa that make them too noticeable in society (p. 81). Thus, through the research, American people mostly believe that transgender is abnormal because they are highly different from non-transgender and it is evident.

\section{CONCLUSION}

LGBT as a minority in the United States is considered as a unity - as one minority group. However, based on the findings, the researcher found that the stereotypes against lesbian, gay, bisexual, and transgender are different from each other. Gay and lesbian are still have neutral stereotypes, while bisexual and transgender are not. Moreover, transgender in the United States has more prejudiced stereotyping than bisexual or other minorities such as lesbian and gay. It happens because of their appearance, which is mostly considered weird and abnormal by Americans.

In summary, stereotypes against minorities in the United States also depend on their appearance and behavior. In this case, transgender people are the most disadvantaged minority group because they appear and 
behave opposite to their gender binary at birth. Thus, it can be concluded that LGBT is not considered as a single entity anymore because each group-lesbian, gay, bisexual, and transgender experienced different stereotypes and challenges.

\section{REFERENCES}

Bronski, M. (2011). A Queer History of the United States. Boston: Beacon Press.

Bull, V. (Ed.). (2008). Straightforward. In Oxford English Dictionary (Fourth Edition). New York: Oxford University Press.

Carter, M. (2014). "Gender Socialization and Identity Theory". Journal of Social Sciences, $\quad 3, \quad 242-263 . \quad$ DOI: $10.3390 /$ socsci3020242.

Gates, G. (2017). "LGBT Data Collection Amid Social and Demographic Shifts of the US LGBT Community". Journal of Public Health, 107(8), 1220-1222. DOI: 10.2105/AJPH.2017.303927.

Gazzola, S., and Morrison, M. (2014). "Cultural and Personally Endorsed Stereotypes of Transgender Men and Transgender Women: Notable Correspondence and Disjunction?". International Journal of Transgenderism, 15, 76-99. DOI: $10.1080 / 15532739.2014 .937041$.

Geiger, W., Harwood, J., and Hummert, M. (2006). "College Students' Multiple Stereotypes of Lesbian: A Cognitive Perspective". Journal of Homosexuality, 51(3), 165-182. DOI: 10.1300/J082v51n03_08.

IMDb. (n.d.). Glee. Retrieved 23 July 2020 from https://www.imdb.com/title/tt4094300.

Jackson, W. (1995). Approaches to Methods. Prentice-Hall: Scarborough, Ont.

Kushnick, H. (2010). "In the Closet: A Close Read of the Metaphor". AMA Journal of
Ethics, 12(8), 678-680. DOI: 10.1001/virtualmentor.2010.12.8.mnar11008 .

Marx, D., and Ko, S. (2019). "Stereotypes and Prejudice". Oxford Research Encyclopedia of Psychology, 00(00), 1-25. DOI:

10.1093/acrefore/9780190236557.013.307

Mediabiasfactcheck. (2019). New York Times. Retrieved 1 June 2020 from https://mediabiasfactcheck.com/new-yorktimes/.

Mediabiasfactcheck. (2019). USA Today. Retrieved 1 June 2020 from https://mediabiasfactcheck.com/usatoday- $2 /$.

Mediabiasfactcheck. (2019). Washington Post. Retrieved 1 June 2020 from https://mediabiasfactcheck.com/washingto n-post/.

Morris, B. (2009). History of Lesbian, Gay, Bisexual, and Transgender Social Movements. Retrieved 20 April 2020 from

https://www.apa.org/pi/lgbt/resources/hi story.

Morrow, D. (2001). "Older gays and lesbians: Surviving generation of hate and violence". Journal of Gay \& Lesbian Social Services, 13(1/2), 151-169.

Nelson, T. (2015). A Movement on the Verge: The Spark of Stonewall. Retrieved 20 April $2020 \quad$ from http://commons.lib.jmu.edu/madrush.

Nytimes. (2020). 2020 Candidates: Pete Buttigieg. Retrieved 07 July 2020 from https://www.nytimes.com/interactive/20 20/us/elections/pete-buttigieg.html.

Nytimes. (2019). At World Cup, US Team's Pride Is Felt by Others, Too. Retrieved 14 July $2020 \quad$ from https://www.nytimes.com/2019/06/29/sp orts/womens-world-cup-lgbt.html.

Nytimes. (2019). Being Gay Hurts Mayor Pete. It Helps, Too. Retrieved 03 July 
2020

from

https://www.nytimes.com/2019/10/29/op inion/pete-buttigieg-gay.html.

Nytimes. (2019). Colorado's Got a Gay Governor: Who Cares?. Retrieved 05 July 2020 from https://www.nytimes.com/2019/01/09/st yle/jared-polis-gay-governor.amp.html.

Nytimes. (2020). Daniel Radcliffe Criticizes J.K. Rowling's Anti-Transgender Tweets. Retrieved 20 July 2020 from https://www.nytimes.com/2020/06/07/art s/JK-Rowling-controversy.html.

Nytimes. (2020). 'For They Know Not What They Do' Review: Where Faith Meets LGBTQ Life. Retrieved 11 July 2020 from

https://www.nytimes.com/2020/06/11/m ovies/for-they-know-not-what-they-doreview.html.

Nytimes. (2020). In Marriage, It's Not About the Dishes. It's About Respect. Retrieved 20 July 2020 from https://www.nytimes.com/2020/02/14/op inion/marriage-happiness-genderhousework.html.

Nytimes. (2019). The ABCs of L.G.B.T.Q.I.A.+. Retrieved 11 July 2020 from https://www.nytimes.com/2018/06/21/st yle/lbtq-gender-language.html.

Ochs, R. (n.d.). A Resource Guide to Coming Out as Bisexual. Retrieved 22 July 2020 from https://caps.ucsc.edu/resources/comingout-guide-bisexual.pdf.

Rowe, J. (2000). Post-Nationalist American Studies. United States: University of California Press.

Tajfel, H. (1963). "Stereotypes". Journal of Race and Class, 3-14.

USA Today. (2020). What's a TERF and why is 'Harry Potter' author J.K. Rowling being called one?. Retrieved 28 July 2020 https://www.usatoday/com/story/news/n ation/2020/06/09/what-terf-definitiontrans-activists-includes-j-krowling/5326071002.

UW News. (2017). Married LGBT older adults are healthier, happier than singles, study finds. Retrieved 20 July 2020 from https://www.washingtonpost.edu/news/2 017/04/13/married-lgbt-older-adults-arehealthier-happier-than-singles-studyfinds/.

Vidal-Ortiz, S. (2008). "Transgender and Transsexual Studies: Sociology's Influence and Future Steps". Sociology Compass, 2(2), 433-450. DOI: 10.1111/j.1751-9020.2007.00086.x.

Waites, M, and Kollman, K. (2009). "The Global Politics of Lesbian, Gay, Bisexual, and Transgender Human Rights: An Introduction". Journals of Contemporary Politics, 15(1), 1-17. DOI: 10.1080 .13569770802674188$.

Washington Post. (2020). Conservatives find unlikely ally in fighting transgender rights: Radical feminists. Retrieved 17 July $2020 \quad$ from https://www.washingtonpost.com/dcmd-va/2020/02/07/radical-feministsconservatives-transgender-rights.

Washington Post. (2019). HUD Secretary Ben Carson makes dismissive comments about transgender people, angering agency staff. Retrieved 17 July 2020 from

https://washingtonpost.com/business/201

9/09/19/hud-secretary-ben-carsonmakes-dismissive-comments-abouttransgender-people-angering-agencystaff/

Washington Post. (2020). Santana began 'Glee' as a typical mean girl. Naya Rivera made her so much more. Retrieved 23 July 2020 from https://www.washingtonpost.com/arts- 
RUBIKON Volume 7/ Number 1

February 2020

entertainment/2020/07/15/naya-riveraglee-santana-appreciation/

Women's Liberation Front Official Website.

(2014). WoLF. Retrieved 29 July 2020

from https://womensliberationfront.org. 